\title{
ESQUISTOSSOMOSE MANSÔNICA AUTÓCTONE NO DISTRITO FEDERAL, BRASIL *
}

Frederico Simões Barbosa**

Carlos E. A. Coimbra Junior **

Barbosa, F. S. \& Combra JR.. C. E. A. Esquitistossomose mansônica autóctone no Distrito Federal, Brasil. Rev. Saúde públ., S. Paulo, 13:108-12, 1979.

RESUMO: Sete casos autóctones de esquistossomose mansônica são descritos no Distrito Federal (Brasil). Todos os casos são de crianças cuias idades variavam de 3 a 13 anos e qule habitavam área suburbana da cidade de Planaltina. Cinco destes casos pertencem a uma mesma familia vivendo às margens de um criadouro de Biomphalaria glabrata onde foram encontrados dois caramulos infectados por Schistosoma mansoni em 229 examinados.

Unitermos: Esquistossomose mansônica, Brasilia, DF, Brasil. Biomphalaria glabrata.

I N T R O D U C A O

O Distrito Federal (DF) tem sido considerado cono foco isolado de esquistossomuse mansônica. Este fato encontra-se refericho enl várias publicaçōes brasileiras e estrangeiras sobre epidemiologia da esquistossomose.

A primeira referência a esquistossomose na região do DF é de Crespo e col.: (1965). Estes autores encontraram Biomphalaria glabrata na bacia do Rio Preto com infecção de $10,26 \%$.

En 1966 Magalhães : (1966) enconntrou B. glabrata na região do Rio Preto em dois focus com infecção por S. mansoni de $2,7 \%$ e $3,3 \%$ e dois casos humanos considerados como autóctones.

Em face dos resultados acima menciona- dos e diante do encontro de um caso seguramente autóctone de esquistossomose em criança nascicla na região de Planaltina (Barbosa e Lavor ${ }^{1}, 1977$ ) decidiu-se investigar a área onde este caso foi registrado.

\section{MÉTODOS}

A região investigada compreende o bairro de $\mathrm{Na}$ Sra. de Fátima, cidade de Planaltina, e as áreas suburbanas adjacentes.

$O$ bairro acima chega até as proximidades de importante criadouro de $B$. glabrata, uma baixada alagada, alimentada pelo Rio Mestre d'Armas e pelas chuvas de verão. O volume da água varia de acordo com as estaçōes do ano. Existem ainda valas no local e um tanque para criação de peixes.

\footnotetext{
* Trabalho realizado com auxílio do Conselho de Desenvolvimento Científico e Tecnológico CNPq.

*: Da Faculdade de Ciências da Saúde da Universidade de Brasilia - 70910 — Brasilia - DF - Brasil.
} 
BARBOSA, F. S. \& COIMBRA Jr., C. E. A. Esquistossomose mansônica autótone no Disirito Federal, Brasil. Rev. Saúde pübl., S. Paulo, 13:108-12. 1979

Foi feito um levantamento coprológico da população vivendo no bairro Na Sra. de Fátima. Foram examinadas 594 pessoa. pela técnica de sedimentação simples, o yue representa cerca de $90 \%$ de toda a população. Um único exame de fezes foi feito para cada pessoa. Os casos positivos foram investigados do ponto de vista epidemiológico.

Caramujos foram coletados na baixada, valas e riachos localizados nas proximida- des do bairro $N^{a}$ Sra. de Fátima. Os caramujos coletados foram examinados à luz e, em seguicia, esmagados para verificação da infecção por S. mansoni.

\section{RESULTADOS}

Os resultados dos exames de fezes para S. mansoni estão contidos na Tabela 1 .

T A B E L A 1

Resultados dos exames de fezes para ovos de Schistosoma mansoni, de acordo com grupos de idade. Bairro Nu Sra, de Fátima, Planaltina, DF, 1978.

\begin{tabular}{|c|c|c|c|c|c|}
\hline \multicolumn{3}{|c|}{$\begin{array}{l}\text { Grupos de } \\
\text { idade }\end{array}$} & $\begin{array}{c}\text { Total } \\
\text { Examinados }\end{array}$ & \multicolumn{2}{|c|}{ Positivos para $S$ mansoni } \\
\hline & Cota! & & 504 & 18 & 2,8 \\
\hline & - & 6 & 180 & 1 & 0.5 \\
\hline & - & 14 & 50.4 & 11 & 5.3 \\
\hline 15 & - & 24 & 62 & 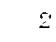 & 3.5 \\
\hline 25 & - & 34 & 46 & $\therefore$ & 4,3 \\
\hline 35 & - & 44 & 53 & - & - \\
\hline 45 & - & 54 & 28 & 1 & 3,5 \\
\hline 55 & e & + & 21 & 1 & 4.7 \\
\hline
\end{tabular}

Os dezoito casos positivos foram investigados do ponto de vista epidemiológico, procurando-se verificar a possivel ocorrência de casos autóctones, particularmente en crianças. Destes, 7 casos são considerados como seguramente autóctones, cujos ciados estão resumidos na Tabela 2 .

Todos os menores do quadro acima, nascidos em Planaltina, pertencem a uma mesma família cujo chefe, H.F.A., de 41 anos, originário da Bahia, infectou-se presumivelmente em seu Estado natal, chegando ao DF há 14 anos atrás. A mulher, I.M.S., de 34 anos teve dois exames de fezes negativos. Todos os filhos, em número de cinco, estavam infectados, sendo que
D.F.S., de 8 anos, foi o primeiro a ter exames de fezes positivos, em agosto de 1976. Nesta época todos seus irmãos tiveram exames de fezes negativos, sendo que M.S.S. teve seu primeiro exame positivo em agosto de 1977 e seus outros três irmãos positivaram apenas em outubro de 1978. Há 4 anos a família vive em um barraco construido a cerca de $40 \mathrm{~m}$ de um criadouro de Biomphalaria glabrata com o qual as crianças tinham contato freqüente.

Os outros dois casos autóctones são de pessoas que chegaram ao DF com um ano de idade, nasceram em áreas não endêmicas e nunca se afastaram para outras regióes do Pais. Ambos habitavam a primeira rua 
BARBOSA, F. S. \& COIMBRA Jr., C. E. A. Esquistossomose mansônica autóctone no Distrito Federal, Brasil. Rev. Saude públ., S. Paulo, 13:108-12, 1979

TA BELA 2

Casos autóctones de infecçâo por S. manson no bairro Nụ Sra. de Fátima, Planaltina, DF, 1976-78.

\begin{tabular}{|c|c|c|c|c|c|c|}
\hline \multirow[t]{2}{*}{ Iniciais } & \multirow[t]{2}{*}{ Idade } & \multirow[t]{2}{*}{ Sexo } & \multirow{2}{*}{$\begin{array}{l}\text { Lucal de } \\
\text { Nascimento }\end{array}$} & \multirow{2}{*}{$\begin{array}{l}\text { No de anos } \\
\text { morando em } \\
\text { Planaltina }\end{array}$} & \multicolumn{2}{|c|}{ No de exames de fezes } \\
\hline & & & & & Negativos & Positivos \\
\hline & Nascidos fora & do Distrito & Federal & & & \\
\hline R.H.A. & 8 & M & Paranã. GO & 7 & - & 1 \\
\hline E.P.S. & 11 & $\mathrm{M}$ & Parnaíba, PI & 10 & - & 1 \\
\hline & Nascidos em & Planaltina, & $\mathrm{DF}$ & & & \\
\hline S.F.S. & 3 & M & $\begin{array}{l}\text { Na Sra, de } \\
\text { Fátima, cida- } \\
\text { de de Planal- } \\
\text { tina }\end{array}$ & - & 2 & 1 \\
\hline M.S.S. & 5 & $F$ & $\begin{array}{l}\text { Vila Buritis, } \\
\text { cidade de } \\
\text { Planaltina }\end{array}$ & 5 & 2 & 1 \\
\hline D.F.S. & 8 & $\mathrm{M}$ & Idem & 8 & 1 & 6 \\
\hline M.S. & 11 & $F$ & $\begin{array}{l}\text { Taquara, zo- } \\
\text { na rural de } \\
\text { Planaltina }\end{array}$ & 11 & 2 & 2 \\
\hline E.A.F.S. & 13 & M & Idem & 13 & 2 & 1 \\
\hline
\end{tabular}

do bairro a cerca de $100 \mathrm{~m}$ do foco $\mathrm{e}$ tinham contato frequiente com as águas naturais.

O estudo epidemiológico revelou ainda cue a população residente nas duas primeiras ruas acima do criadouro de $B$. glabrata é a que tem maior contato com o foco. Estas águas são freqüentemente utilizadas para lavagem de roupa, pesca e folguedo de crianças. As casas do bairro nāo possuem água encanada e a população que não tem cacimbas supre-se das águas do criadouro para uso doméstico.

Há um caso adicional yue não foi classificado como autóctone, mas que é bastante suspeito. Trata-se de C.T.F. de 13 anos, sexo feminino, nascida em Campina Grande, $P B$, e que mora em Planaltina há 8 anos. Embora ela tenha afirmado nunca ter se afastado de Campina Grande em direção ao litoral, foi preferivel classificar este caso como suspeito.
Caramujos infectados foram encontrados apenas no criadouro acima descrito. Neste local foram coletados, de $31 / 1 / 78$ a $21 / 9 / 78$, 229 exemplares de $B$. glabrata, dois dos quais estavam positivos para cercárias de S. mansoni $(0,87 \%)$.

\section{COMENTARIOS E CONCLUSOES}

Os primeiros dois casos de esquistossomose, considerados como autóctone no DF, foram assinalados por Magalhães 3 (1966), em pessoas nascidas em Formosa, GO, um com 16 anos e o outro com 34 anos. Ambos tinham contato com áreas de cultivo de arroz em zona rural de Planaltina. Foram encontrados caramujos infectados na percentagem de 2,7 e 3,3.

A população fixa das áreas acima (córregos Sāo José e Capāo Rico) era extremamente baixa. Os trabalhadores que fre- 
qüentavam os arrozais constituiam população bastante móvel e inconstante.

Anteriormente Crespo e col.: (1965) haviam assinalado taxa muito elevada de infecção natural de B. glabrata por S. mansoni em Grotão, área rural de Planaltina. Em 1966, entretanto, Magalhães 3 (1966) não mais encontrou caramujos infectados nesta área. Também Barreto* (1978) em pesquisas sistemáticas em áreas do Rio Preto (DF), e Formosa (GO), nos anos de 1973-74 não encontrou um só caramujo, B. glabrata, infectado dentre 3.700 examinados.

A impressão que se tem é de que os caramujos encontrados infectados e a baixa densidade dos três focos acima assinalados, todos na bacia do Rio Preto, não foram capazes de manter a infecção, podendo os casos humanos assinalados ser considerados como) espurádicus.

Entretantu, o vale do Rio Preto, pertencente à bacia do Rio São Francmisco, é potencialmente um foco importante da doença pela presença de uma população muito elevada de $B$. glabrata, embora seja, no momento, uma das regióes menos habitadas do DF.

No presente trabalho deve ser registrado que pupulações bem estabelecidas de $B$. glabrata foram encontradas em afluente do Rio São Bartolomeu que, por sua vez, compóe a bacia do Prata. Este fato permite supor que $B$. glabrata possa se expandir atingindo regiōes distantes do centro e sul do País.

Deve-se ainda assinalar que todas as regiões, nas Américas, onde $B$. glabrata foi assinalado, constituiriam-se em focos ativos de transmissāo de esquistossomose.
Os casos aqui registradus são seguramente autóctones. O estudo de casos da familia de H.F.S. mostrou como as infecções foram se sucedendo. Há, ou havia**, transmissão ativa na área.

$\mathrm{O}$ bairro de $\mathrm{Na}$ Sra. de Fátima está situado um pouco acima do criadouro estudaclo neste trabalho. Apenas 3 casas estão localizadas nas proximidades do criadouro. Entretanto, loteamentos estão sendo feitos no bairro, prevendo-se, assim, que casas ou casebres serão construidos cada vez mais próximos do foco de $B$, glabrata.

As áreas do DF habitadas por B. glabrata devem ser consideradas como altamente favoráveis à instalação da doença, faltando apenas concentração de populações marginalizadas nas condições em que vivem usualmente no Pais para que passem a "fabricar" focos produtivos da doença. Os demais fatores condicionantes da esquistossomose já existem na região.

Deve ainda ser mencionado que a área investigada neste trabalho foi muito limitada e que outras regiões do DF habitadas por B. glabrata, assin como o município de Formosa, GO, devem ser investigadas cuidadosamente a fim de que se possa medir a extensão do problema.

\section{AGRADECIMENTOS}

Aos técnicos Delfino G. Curado, da Universidade de Brasília, e Jovelino I. Coelho, da SUCAM (Superintendência de Campanhas de Saúde Pública) pela valiosa cooperação.

\footnotetext{
* A. Barreto - comunicação pessoal, 1978.

** Atualmente a SUCAM, do Ministério da Saúde, faz trabalho intenso de controle da doença na região
} 
BARBOSA. F. S. \& COIMBRA Jr.. C. E. A. Esquistossomose mansônica autóctone no Distrito Federal. Brasil. Rer Sauide públ. S. Palilo. 13:108-12, 1979

BARBOSA, F. S. \& COMBra JR., C. E. A. /Antochthonous cases of schistosomiasis mansoni in the Federal District, Brazil.J Rev. Saúde públ., S. Paulo, 13: $108-12, \quad 1979$.

ABSTRACT: Seven antochthonous cases of schistosomiasis mansoni are described in this paper. All of them refer to children, 3 to 13 l'ears old, living in Planaltina, Federal District, Brazil. Five out of the seven cases belong to the same family living for 14 years in Planaltina. For the last 4 years this family has lived in a wooden hut 40 meters distant from a breeding place of $\mathrm{B}$. glabrata. Of the 229 snails examined, two were naturally infected with S. mansuni.

UNiter.us: Schistosomiasis, Brasilia, DF, Brazil. Biomphalaria glabrata.

\section{REFERENCIAS BIBLIOGRAFICAS}

1. BARBOSA. F. S. \& LAVOR, A. C H. Esquistossomose autóctone no Distrito Federal. In: Congresso Brasilerry de Higiene. São Paulo. 197̈. Resumo dos trabalios. São Paulo. 1977. Trabalho 11.2 .

2. CRESPO. T. M. et al. Esquistossomose em áreas do Distrito Federal, Rer. bras. Malar., $17: 367-9,1965$. $\therefore$ MAGALHAES. L. A, Moluscos planorbidtur do Distrito Federal. Campinas. 1966. [Tese de Doutoramento - Faculdade de MIedicna da tniversidade de Campinas]

Recebido para publicacto em ?h/01/1979

Aprovalo sara publacaça cm $22 / 03 / 1979$ 